\title{
Modelo Pedagógico para o Desenvolvimento de Competências Docentes em Contabilidade por Educação a Distância
}

\author{
Maria Ivanice Vendruscolo ${ }^{1}$, Patrícia A. Behar ${ }^{2}$, Magda Bercht ${ }^{2}$ \\ ${ }^{1}$ Departamento de Ciências Contábeis- Universidade Federal do Rio Grande do Sul \\ Av. João Pessoa, 52 - 90.040-000, Porto Alegre - RS - Brazil \\ ${ }^{2}$ Instituto de Informática - Universidade Federal do Rio Grande do Sul (UFRGS) \\ Av. Paulo Gama, 110 - prédio 12105 - 90040-060, Porto Alegre - RS - Brazil \\ \{maria.ivanice, patricia\} @ufrgs.br, \{bercht\} @inf.ufrgs.br
}

\begin{abstract}
Resumo. O artigo apresenta a construção do Modelo Pedagógico para o Desenvolvimento de Competências Docentes em Contabilidade por Educação a Distância (MPCCEaD). O Modelo traz a visão do processo de ensino e aprendizagem centrada na atividade do professor-aluno, na construção de conhecimentos à luz da Teoria da Epistemologia Genética e no desenvolvimento de competências com os fundamentos da Educação a Distância. O produto resultante amplia e aprofunda a formação stricto sensu, subsidia políticas institucionais de formação continuada e a proposição de iniciativas para desenvolver competências docentes da Educação Superior, em geral, e em particular em Contabilidade, de forma sistemática.
\end{abstract}

\begin{abstract}
This article presents the construction of the Pedagogical Model for the Development of Teaching Competencies in Accounting Distance Learning (MPCCEaD). The model brings the teaching and learning process focused view in the learner's activity in the construction of knowledge in the light of the theory of Genetic Epistemology and the development of teaching skills, with the fundamentals of Distance Learning. The resulting product extends and deepens the training carried out in strict sense program subsidizes institutional policies linked to the continuing education of teachers of higher education in general and in particular Accounting and proposing initiatives to develop them systematically.
\end{abstract}

\section{Introdução}

O Ministério da Educação (MEC) brasileiro vem envidando esforços para fomentar a EAD e a incorporação das Tecnologias da Informação e Comunicação (TIC) nas tradicionais metodologias didático-pedagógicas [Almeida, 2003; Behar, 2009; Moran, 2011]. Esse esforço acompanha uma tendência mundial nas modalidades de educação presencial e a distância de forma a ampliar o acesso à Educação [Almeida, 2003; Peters, 2009; Moran, 2011]. Por sua vez, os modelos educacionais vêm evoluindo significativamente, impulsionados pelos impactos e mudanças de forma abrangente na Educação [Behar, 2009; Pereira, et al., 2011; Avendaño-Castro, 2013]. Com base nessa realidade, os agentes envolvidos com o sistema educacional necessitam acompanhar esses avanços e mudanças, bem como introduzir as TIC nas práticas pedagógicas dos docentes (Almeida, 2003). Nestas circunstâncias, os professores de Contabilidade 
também são desafiados a desenvolverem novas competências para o exercício da docência [Accounting Education Change Commission, 1999].

Os estudos na área contábil têm revelado que a formação dos seus professores não contempla a abordagem de competências pedagógicas [Nossa, 1999; Laffin, 2005; Andere e Araújo, 2008; Marshall et al. 2010]. Tal situação leva a refletir: Como e quais os modelos pedagógicos para desenvolver competências docentes em Contabilidade? Quais as especificidades para a Educação Superior em Contabilidade? Quais modelos são pertinentes a EAD?

É nesse contexto reflexivo que se insere este estudo aplicado à Educação Superior em Contabilidade em nível de graduação. Seu foco de interesse é a busca de um modelo pedagógico de aprendizagem a distância, em geral, que contemple as especificidades da área contábil na formação docente. O objetivo deste artigo é apresentar a construção do Modelo Pedagógico para o Desenvolvimento de Competências Docentes em Contabilidade por Educação a Distância (MPCCEaD). Por modelo pedagógico entende-se um instrumento de caráter teórico que possibilita a interpretação, a projeção e o ajustamento da realidade pedagógica, construído para representar o processo de ensino e aprendizagem [Mendoza, 2001; Moreno, 2003; Ocaña, 2009; Behar, 2009]. Por competências, a "capacidade do indivíduo mobilizar e combinar conhecimentos, habilidades e atitudes entre si para o alcance de um determinado objetivo ou na resolução de uma determinada situação, inserida num contexto, seja ele profissional, social, educacional, cultural ou político" [Vendruscolo e Behar, 2015, p. 1675].

\section{Procedimentos metodológicos}

$\mathrm{Na}$ construção do MPCCEaD foram adotados os procedimentos de concepção, planificação, implementação e validação [Behar, 2009; Abbasi, 2013], atendendo à metodologia de elaboração e gerenciamento de projetos, composta das fases de iniciação, planejamento, execução e controle [Project Management Institute, 2008]. A fase de Iniciação consistiu na definição do escopo do projeto e na sua concepção. Esta foi obtida com base na questão de pesquisa e nas diretrizes teóricas sobre construção de conhecimentos, desenvolvimento de competências docentes e elaboração de modelos pedagógicos para a EAD, respeitando as especificidades observadas na área contábil. A fase de planejamento contempla o procedimento de planificação que consiste na elaboração do plano de ação para a construção do modelo teórico concebido e atende aos quesitos da arquitetura pedagógica para elaboração de modelos pedagógicos na modalidade EAD nos aspectos [Behar, 2009]: i) organizacionais - objetivos da aprendizagem, definição de papéis, perfis dos atores, tempo e espaço; ii) conteúdos tipo de material e/ou elemento(s) utilizado(s), material instrucional, software educacional, páginas web, objetos de aprendizagem; iii) metodológicos - seleção das técnicas, procedimentos, recursos informáticos, sequência didática; iv) tecnológicos definição do Ambiente Virtual de Aprendizagem (AVA); funcionalidades e/ou recursos de comunicação e interação. O planejamento e a organização das atividades do curso contemplam as orientações metodológicas para um projeto de desenvolvimento de competências na área contábil [Abbasi, 2013]. Com o modelo teórico concebido, os dados bibliográficos foram coletados para desenvolvimento da arquitetura pedagógica EAD, procedeu-se a elaboração do plano de ensino, a preparação dos materiais e a 
V Congresso Brasileiro de Informática na Educação (CBIE 2016)

Anais dos Workshops do V Congresso Brasileiro de Informática na Educação (CBIE 2016)

organização do AVA, contemplando a Matriz de Competências Docentes em Contabilidade [Vendruscolo e Behar, 2015].

\section{Construção do Modelo Pedagógico}

\subsection{Concepção do MPCCEaD}

O MPCCEaD é orientado ao desenvolvimento de competências docentes de professores do eixo de formação profissional de cursos de graduação em Ciências Contábeis no Brasil, contemplando uma proposta pedagógica interdisciplinar para um Curso de PósGraduação Stricto Sensu em Competências Docentes em Contabilidade. Por consequência, o Modelo decorre de um sistema de premissas observadas nas especificidades da área contábil e de construtos teóricos sobre modelos pedagógicos que suportam a organização de práticas pedagógicas para a EAD. O Modelo é resultado da reflexão, elaboração, construção e aplicação dos eixos teóricos da Teoria da Epistemologia Genética [Piaget, 1973, 1995] e do desenvolvimento de competências docentes [Gaspar, 2004; Macedo, 2004; Aldana, 2008; Nóvoa, 2009; Imbernón, 2009] por meio da educação a distância [Behar, 2009; Moran, 2011], relacionados entre si.

Nesta perspectiva, o pressuposto epistemológico que sustenta o MPCCEaD é o construtivismo, paradigma educacional interacionista. $\mathrm{Na}$ concepção epistemológica construtivista, o conhecimento prévio influencia as observações sobre a ação, determinando a maneira pela qual a realidade é percebida [Piaget, 1977, 1995]. Conforme defendido por Piaget (1973), o sujeito desenvolve-se biológica, social e cognitivamente por sua ação e sua interação com o objeto do conhecimento. Por sua vez, o desenvolvimento cognitivo de competências docentes emerge da ação e da reflexão dos próprios professores sobre seu fazer pedagógico, de forma a lhes possibilitar, permanentemente, a reconstrução e a recontextualização de suas competências [Gaspar, 2004; Macedo, 2004; Nóvoa, 2009; Imbernón, 2009]. A elaboração contínua de operações sobre sua ação pedagógica desenvolve as estruturas cognitivas no exercício da docência (Gaspar, 2004). Portanto, as duas plataformas teóricas são convergentes e se aplicam no embasamento do desenvolvimento das competências docentes, objeto do MPCCEaD. Ancorado nessas instrumentalizações teóricas, o Modelo é concebido para promover reflexões sobre a prática pedagógica, partindo dos níveis prévios de competências docentes (conhecimentos, habilidades e atitudes). A aprendizagem é dinâmica, provocada por situações de desequilíbrios cognitivos e retomadas do equilíbrio em patamares superiores que possibilitem ao professor-aluno a construção de novos conceitos.

\subsection{Planificação do MPCCEaD}

O detalhamento da planificação do MPCCEaD segue as orientações metodológicas de Abbasi (2013) na elaboração do plano de ação e base teórica de Behar (2009) para modelos pedagógicos na modalidade de EAD, constituídos pelos elementos básicos: arquitetura pedagógica (seção 3.2.1) e estratégia para aplicação da arquitetura (seção 3.2.2). O pressuposto epistemológico norteia a definição de todos os aspectos dos elementos do Modelo. A arquitetura pedagógica do MPCCEaD representa o conjunto articulado dos aspectos organizacionais, de conteúdos, metodológicos e tecnológicos para um Curso de Pós-Graduação Stricto Sensu em Competências Docentes em Contabilidade na modalidade EAD, bem como as estratégias de sua aplicação. 
V Congresso Brasileiro de Informática na Educação (CBIE 2016)

Anais dos Workshops do V Congresso Brasileiro de Informática na Educação (CBIE 2016)

\subsubsection{Aspectos organizacionais da arquitetura pedagógica do MPCCEaD}

O MPCCEaD é concebido, planejado e esquematizado para contribuir no desenvolvimento de competências docentes em Contabilidade por EAD por Curso Stricto Sensu, com a participação ativa dos professores nos processos de construção de conhecimentos, desenvolvimento de habilidades e promoção de atitudes relacionadas ao exercício da docência. Para o alcance do objetivo educacional, a organização curricular do Curso Stricto Sensu prevê no mínimo 4 (quatro) semestres, contemplando 24 (vinte e quatro) meses. O currículo está disposto em atividades de ensino em formato de seminários e disciplinas, por tópicos temáticos de linhas de pesquisa, decorrentes da Matriz de Competências Docentes em Contabilidade [Vendruscolo e Behar, 2015]: i) Competências Educacionais - Fundamentos da Docência Superior, As Teorias Pedagógicas, Metodologias e Didática no Ensino Superior e Tecnologias da Informação e Comunicação na Educação; ii) Competências Cognitivas - Planejamento e Organização do Processo de Ensino e Aprendizagem Contábil, Gestão, Análise e Reflexão na Docência e Metodologias de Pesquisa em Contabilidade (Projeto); iii) Competências Sociais - Trabalhos em Equipe, Política Institucional e Ética na Educação, Afetividade e Cognição; iv) Competências Acadêmicas - Projeto, Artigos, Dissertação/ Tese e Defesa.

Atendendo o escopo do MPCCEaD, o Curso Stricto Sensu apresenta uma estrutura de governança representada por uma coordenação geral e uma equipe multidisciplinar, com diferentes papéis a desempenhar, estabelecidos, distintamente, para definição de suas atribuições, responsabilidades e direitos: i) coordenação responsável pelo planejamento e implementação do projeto do curso EAD na IES, pela formação do corpo docente, pelo gerenciamento da grade curricular, pela elaboração do orçamento e pelas equipes de trabalho; conta com o apoio de um núcleo pedagógico institucional, um suporte tecnológico e uma equipe de trabalho composta por professores, tutores, secretaria e técnicos (administrativos, financeiros, educacionais e de tecnologia); ii) professor conteudista - conceber os materiais a serem utilizados nas atividades pedagógicas, com a colaboração de equipes de desenvolvimento do conteúdo e web designers; iii) professor formador - responsável por planejar e organizar o processo educativo, de criar e aplicar as situações que promovam a aprendizagem, de estabelecer os materiais instrucionais e as atividades educativas, pela mediação pedagógica entre os objetivos educacionais e os interesses de aprendizagem dos professores-alunos e pelos processos e os critérios avaliativos; seu papel é incentivar a reflexão sobre a prática pedagógica dos mesmos, promover os desequilíbrios cognitivos que lhes possibilitem construções e reconstruções num patamar superior de suas competências docentes, à luz de novos conhecimentos; iv) tutor e monitor responsáveis pelo acompanhamento dos professores-alunos no processo de ensino e aprendizagem proposto pelo professor formador; a eles cabe o incentivo da participação, o apoio e a orientação na realização das atividades individuais e de grupo, a promoção das interações no AVA e o feedback das atividades realizadas pelos professores-alunos, segundo orientações do docente; v) professor-aluno - é esperado um papel ativo (postura participativa, interativa e cooperativa no ambiente) no processo de desenvolvimento de suas competências docentes: navegar e explorar os materiais instrucionais, compartilhar experiências, realizar as tarefas e as discussões de forma colaborativa; o Modelo leva em consideração a condição de educador, a formação inicial e as experiências pedagógicas anteriores dos professores-alunos. 
O alinhamento pedagógico entre professores, tutores e monitores é proporcionado por meio de oficinas de capacitação e orientações gerais. Para tanto, inicialmente, o MPCCEaD promove a organização espacial e temporal para realização das atividades propostas, o monitoramento das aprendizagens realizadas e $\mathrm{o}$ estabelecimento de comunidades de aprendizagens no AVA. O plano de trabalho da equipe pedagógica do curso stricto sensu contempla as atividades: i) do professor planejar e organizar didática e pedagogicamente a disciplina, definir as metodologias a serem empregadas, elaborar o plano de ensino, elaborar os materiais educacionais, selecionar os materiais para disponibilização aos participantes, estruturar o ambiente virtual de aprendizagem, disponibilizar os conteúdos programáticos, elaborar as avaliações e gabaritos, corrigir as avaliações, elaborar o plano de trabalho do tutor, supervisionar as atividades do tutor, interagir com os participantes em chats, fórum, $e$ mails, salas de entregas, entre outras ferramentas, divulgar os conceitos finais no sistema da IES; ii) do tutor - atendimento online ao participante, em consultas individualizadas ou em grupo, ajudá-los a compreender os materiais do curso através das discussões e explicações, incentivar a realização das tarefas propostas pelo professor; iii) do monitor - atendimento online ao participante, em consultas individualizadas para colaborar no uso das ferramentas do AVA, ajudá-los a compreender os materiais do curso através das discussões e explicações, incentivar a realização das tarefas com o uso de TIC. A seleção destes agentes tem por parâmetros as competências específicas em EAD [Silva, 2012].

Os suportes técnico, pedagógico e administrativo são fornecidos por profissionais multidisciplinares da IES, compostos por equipes de secretaria de EAD, de núcleo de apoio pedagógico e de programa de pós-graduação. As principais responsabilidades das equipes de apoio são: i) técnico - capacitação das equipes de trabalho no tocante ao aperfeiçoamento pedagógico por intermédio da utilização das TIC, contribuição na seleção dos tutores, suporte pedagógico à plataforma EAD, apoio dos polos presenciais da UAB; ii) pedagógico - apoio pedagógico na produção de materiais educacionais digitais e suporte pedagógico; iii) administrativo - divulgação, inscrição e matrículas no curso, registro e atualizações dos dossiês dos alunos, acompanhamento das normatizações da pós-graduação, providenciar os trâmites para emissão dos certificados de conclusão do curso, organização dos registros dos alunos, controle orçamentário do curso, documentação do curso e demais atividades administrativas e financeiras. A infraestrutura material (equipamentos, laboratórios, bibliotecas, midiatecas, centros de documentação entre outras), e serviços de atendimento aos professores-alunos da IES são dimensionados ao número de participantes, à abrangência territorial e aos recursos tecnológicos empregados, atendendo aos demais aspectos da arquitetura pedagógica.

\subsubsection{Aspectos de conteúdo da arquitetura pedagógica do MPCCEaD}

Os aspectos de conteúdo do MPCCEaD contemplam a previsão, a seleção, a preparação de materiais instrucionais e a indicação de bibliografia, atendendo as ementas das atividades de ensino do Curso Stricto Sensu. A previsão objetiva a identificação de materiais instrucionais digitais que contribuam para o embasamento teórico-prático, favoreçam a integração dos agentes do processo educativo e o papel ativo do professoraluno, relacionados ao tipo de conteúdo planejado. Para tal, são realizadas buscas de materiais instrucionais digitais de domínio público, reutilizáveis de formação de 
professores no contexto da EAD disponíveis, principalmente, na web, em repositórios digitais, em midiatecas, entre outros. Os objetos digitais utilizados são públicos e apresentam as informações relativas à autoria e aos créditos atribuídos aos seus elaboradores, obtidos online, licenciados pelo Creative Communs Licences. Os conteúdos interativos indexados (via web) são selecionados, preferencialmente, em diversas mídias e linguagens: textos online, vídeos, áudios, hipertextos, páginas web, hiperlinks, bibliotecas virtuais, softwares educacionais, e-books, audiobooks, imagens, ferramentas de autoria e objetos de aprendizagem, a fim de envolver diferentes estilos de aprendizagem. Para conteúdos que não se identificam materiais disponíveis, são preparados em áudios para otimização espacial e temporal, a exemplo de utilização em momentos de deslocamentos.

\subsubsection{Aspectos metodológicos da arquitetura pedagógica do MPCCEaD}

O planejamento metodológico do MPCCEaD é realizado para a participação ativa dos professores-alunos no processo de desenvolvimento progressivo de suas competências docentes. Ele sustenta metodologicamente a interação entre os professores-alunos (sujeito) e as competências docentes (objeto), mediada por TIC em um ambiente virtual de aprendizagem pelos professores formadores. As competências docentes são desenvolvidas com base nos conhecimentos prévios dos professores-alunos, pelas ações e coordenações de ações promovidas nas atividades do curso. Para tal, o processo de ensino e aprendizagem é centrado na ação do professor-aluno sobre os objetos, com proposição e acompanhamento de atividades síncronas e, principalmente, assíncronas, disponibilizadas online no ambiente virtual. Os professores-alunos dispõem de períodos flexíveis à participação, à realização e à evolução nas atividades dispostas em tópicos no AVA. A organização metodológica da plataforma permite percursos moduláveis ao não restringir, priorizar ou limitar acessos às atividades e aos materiais instrucionais. Adicionalmente, para que os professores-alunos possam avançar de forma autônoma, são disponibilizados diferentes objetos virtuais de aprendizagem.

O Planejamento pedagógico das atividades de ensino do MPCCEaD atende a sequência didática: i) explorar conhecimentos prévios - narrativas do participante sobre os conhecimentos práticos relativos aos temas a serem explorados na atividade de ensino. descrição da sequência de ações de sua prática pedagógica, ilustrando o que faz para planificar as suas aulas; ii) desenvolver esquemas assimiladores - leitura prévia de textos online (capítulos ou e-books) e/ou assistir vídeos, realização de pesquisas envolvendo os temas a serem estudados; iii) agir sobre os objetos com coordenação de ações e promover a relação entre os conteúdos e conhecimentos prévios - estruturação de resumos e de esquemas, elaboração de comentários e discussões nos fóruns, realização de atividades teóricas-práticas que promovam a reconstituição de suas ações, entre outras, sobre os temas de estudo; análises comparativas de sua prática com os elementos dos temas de estudo (representações em um todo coordenado). apresentação do resultado de suas pesquisas relacionadas com a sua prática docente, por vídeos, trabalhos de campo, postagens de texto, discussões nos fóruns, registros no diário, entre outras; iv) proporcionar novos patamares de reflexionamento - resolução de problemas com base nos conteúdos anteriores e questões formuladas pelo professor; elaboração de novas práticas e/ou identificação de possibilidades de modificações; v) proporcionar a reflexão - reflexão sobre a sua prática pedagógica para permitir a identificação de conexões entre a teoria e a prática favorecendo novas construções com base nos 
reflexionamentos precedentes; vi) promover a meta-reflexão - reelaboração do plano de ensino e aprendizagem e reconstrução de materiais didáticos em novos patamares à luz dos novos conceitos construídos sobre as competências docentes dos professores.

A avaliação da aprendizagem e do desempenho dos professores-alunos no curso em relação aos objetivos educacionais é processual, realizada com base no feedback das atividades síncronas e assíncronas propostas, de responsabilidade dos professores formadores e tutores das atividades de ensino. Os instrumentos de avaliação são as próprias ferramentas do AVA adotadas para comunicação, realização de atividades e de postagens de materiais no ambiente e os dados são coletados por intermédio dos registros nas diferentes ferramentas. Os critérios de avaliação incluem qualidade das interações e das contribuições, participações individuais e de grupos, taxa de efetividade na realização das tarefas individuais e de grupos, pontualidade, índice de aproveitamento do participante no curso. Atendendo à legislação vigente, ao final do curso realiza-se uma avaliação presencial, via polos presenciais.

\subsubsection{Aspectos tecnológicos da arquitetura pedagógica do MPCCEaD}

O planejamento e a organização dos aspectos tecnológicos do MPCCEaD são realizados em consonância com os demais aspectos da sua arquitetura pedagógica, norteados pelo pressuposto epistemológico que o fundamenta. Para atender aos elementos da arquitetura pedagógica definidos, anteriormente, o Modelo é suportado tecnologicamente pela Plataforma Moodle. Na definição da plataforma, leva-se em consideração a disponibilização institucional, a robustez do sistema, o padrão de operacionalidade SCORM, que suporta a exportação e a importação de conteúdos, a página ser personalizável, a infraestrutura tecnológica para a mediação pedagógica (ferramentas e recursos), as características de controle e o gerenciamento de integrantes, assim como a flexibilidade e a segurança na sua adoção e a facilidade de navegação aos usuários (professor, tutor, monitor e professor-aluno). O Moodle fornece a infraestrutura tecnológica para estabelecer e organizar o AVA centrado no professor-aluno (usuário), para assegurar a interação e a comunicação pretendidas aos agentes e a mediação pedagógica para alcance dos objetivos educacionais. Ela é composta por suas funcionalidades e recursos síncronos e assíncronos para: comunicação e interação (recursos de escrita, visuais e audiovisuais), disponibilização de materiais instrucionais, cronograma, modularização do conteúdo, proposição das atividades, suporte aos trabalhos individuais e coletivos, postagens de tarefas e avaliações. A fim de familiarização com a tecnologia adotada, ao iniciar o curso é realizada uma oficina para capacitar o professor-aluno nas ferramentas e recursos contemplados na plataforma e nas competências da EAD para garantir sua presença social no AVA.

\subsubsection{Estratégias de aplicação do MPCCEaD}

Alinhadas com a concepção epistemológica, com os aspectos metodológicos da arquitetura pedagógica e com os objetivos do MPCCEaD, as estratégias de aplicação objetivam o desenvolvimento cognitivo das competências docentes dos professores de Contabilidade, pela combinação de diferentes estratégias dinâmicas, articuladas e flexíveis, aplicadas na prática pedagógica no AVA. As principais estratégias previstas no Modelo, tendo por base as competências docentes mapeadas na pesquisa, são leitura, escrita, pesquisa, reflexão da prática pedagógica, aplicação prática dos conceitos, solução de problemas, desenvolvimento de projetos, reconstrução da prática e 
participação ativa. As estratégias de aplicação selecionadas provocam processos cognitivos que permitem aos professores-alunos estabelecerem relações com seus conhecimentos prévios, incertezas e questionamentos, uma vez que o processo de tomada de consciência não é imediato. Elas privilegiam as condições que favoreçam a reflexão sobre a prática educativa dos professores-alunos e promovam inovações em suas próprias disciplinas ministradas.

Os professores formadores do curso, colocando o seu modelo pessoal em prática, podem aplicar e ou adequar diferentes estratégias, intervir no processo de aprendizagem de forma a criar as condições à construção e à reconstrução (no plano da representação) e propor atividades que incentivem: i) a autonomia dos participantes: preparação prévia de questões, relatório sobre as análises realizadas, individuais e em grupo, artigos sobre os tópicos estudados no curso, entre outras; ii) a colaboração, a interação e a afetividade entre os participantes; iii) o envolvimento do grupo através do entrelaçamento de ações, registros de atividades (portfólios) para consulta dos demais, para avaliação e para autoavaliação; iv) discussões de grupos em fóruns, chats, webconferências sobre as temáticas estudadas, promovendo comparações e análises sobre novas possibilidades de ação pedagógica, com os professores e tutores, entre colegas. No início de cada atividade de ensino e ou no seu decorrer, os professores formadores podem capturar as expectativas de aprendizagem, necessidades de assimilação e conhecimentos prévios nos registros do Diário do Participante e nas respostas ao Questionário de Informações do Docente, acoplados à plataforma.

\subsection{Implementação do MPCCEaD}

A preparação e a organização do ambiente de aprendizagem deve atender aos aspectos previstos na planificação do Modelo, organizados em matriz de atividades por elementos educacionais do processo, contemplando no mínimo: i)Tópicos de Apresentação: contendo o objetivo do Curso, indicação dos professores, tutores e monitores, bem como suas disponibilidades de atendimento online, Vídeo de Apresentação, Plano de Ensino e Aprendizagem, Cronograma de Atividades, Questionário de Informações do Docente (a ser respondido ao iniciar o Curso), Vídeo de Apresentação da Monitoria e Fórum de Contato com a Monitoria; ii) Tópico Nos Conhecendo: com orientações de revisão e atualização do Perfil dos participantes e inclusão de foto perceptível e participação na Enquete EAD; iii) Tópico Diretório do Participante: um espaço para registro e acompanhamento da evolução das atividades durante o curso e postagem de materiais e tarefas, contendo: Diário, Sala de Entrega de Materiais (postagem de arquivos), Glossário para contribuições coletivas, Sala de Webconferência, Fórum dos Grupos, Sala de Bate-Papo para contatos com os Colegas; iv) Tópicos Semanais do Programa: contendo as atividades e materiais disponibilizados, conforme o planejamento do Cronograma de Atividades; v) Tópicos Materiais de Consulta e Bibliografia. Com os procedimentos de implementação do MPCCEaD providenciados e atendidos aplica-se o Modelo na IES.

\section{Considerações Finais}

O MPCCEaD é concebido em nível de um curso stricto sensu e visa contribuir no desenvolvimento de competências docentes de professores do eixo de formação profissional de cursos de graduação em Ciências Contábeis no Brasil. O pressuposto epistemológico construtivista, com ênfase do paradigma interacionista da ação docente 
e da condução da aprendizagem, orienta a definição da arquitetura pedagógica e o estabelecimento das estratégias de aplicação do Modelo pela EAD. O uso das TIC viabiliza a construção de um ambiente de aprendizagem com flexibilização de horários e ampliação das condições de sua realização com a integração das tecnologias na educação.

A construção do MPCCEaD, de caráter interdisciplinar pela interface de outras áreas do conhecimento, amplia e aprofunda a formação realizada em programa stricto sensu e aprimora com a proposta de qualificação pedagógica dos professores da área contábil. Respeitando as especificidades da área contábil, o Modelo proporciona a discussão e a reflexão contextualizada do papel do professor sobre a sua realidade social e as exigências de formação de profissionais especializados para atuarem nas organizações. Ao se investir na formação docente, contribui-se, também, para construção de conhecimentos acadêmicos e profissionais, em geral, e em particular, os dos profissionais da área contábil. Logo, o MPCCEaD - Modelo Pedagógico de Desenvolvimento de Competências Docentes em Contabilidade por EAD representa um produto de pesquisa com utilidade prática na construção de competências docentes específicas da Educação Superior, em geral, e em particular, em Contabilidade, beneficiando a comunidade acadêmica e aproximando a pesquisa da sociedade, em consequência, pela perspectiva de melhoria na formação profissional do egresso da IES. Nesse sentido, o produto de pesquisa pode contribuir na proposição e ou na reformulação de programas de formação stricto sensu em Ciências Contábeis. Também, na oferta, pelas IES, de capacitação de professores de Contabilidade direcionada ao desenvolvimento de suas competências docentes. Por fim, sugere-se futuras investigações sobre as práticas pedagógicas dos professores de Contabilidade relacionadas à ação de seus antigos professores, bem como a realização de pesquisas do docente no papel de aprendiz.

\section{Referências}

Abbasi, N. (2013). Competency approach to accounting education: a global view. Journal of Finance and Accountancy, Flórida, v. 13, [s.n.].

Accounting Education Change Commission. (1999). The Accounting Education Change Commission: its history and impact.

Aldana, I. A. M. (2005). Aprendizaje y desarrollo de competencias. Bogotá: Cooperativa Editorial Magistério.

Almeida, M. E. B. (2003). Educação a distância na internet: abordagens e contribuições dos ambientes digitais de aprendizagem. Educação e Pesquisa, São Paulo, v. 29, n. 2, p. 327-340, jul./dez.

Andere, M. A. e Araújo, A. M. P. (2008). Aspectos da formação do professor de ensino superior de ciências contábeis: uma análise dos programas de pós-graduação. Revista Contabilidade \& Finanças, São Paulo, v. 19, n. 48, p. 91-102, set./dez.

Avendaño-Castro, W. R. (2013). Un modelo pedagógico para la educación ambiental desde la perspectiva de la Modificabilidad Estructural Cognitiva. Revista Luna Azul, Colômbia. n. 36, p. 110-133, enero/jun.

Behar, P. A. (2009). Modelos pedagógicos em educação a distância. In: Behar, P. A. (Org.). Modelos pedagógicos em educação a distância. Porto Alegre: Artmed 
V Congresso Brasileiro de Informática na Educação (CBIE 2016)

Anais dos Workshops do V Congresso Brasileiro de Informática na Educação (CBIE 2016)

Gaspar, M. I. (2004). Competências em questão: contributo para a formação de professores. Discursos. Série: perspectivas em educação, p.55-71, dez.

Imbernón, F. (2009). Formação docente e profissional: formar-se para a mudança e a incerteza. 7. ed. Tradução de Silvana Cobucci Leite. São Paulo: Cortez.

Laffin, M. (2005). De contador a professor: a trajetória da docência no ensino superior da contabilidade. Florianópolis: Imprensa Universitária.

Macedo, L. (2004). Desafios à prática docente reflexiva. In: MACEDO, L. Ensaios psicológicos: como construir uma escola para todos? Porto Alegre: Artmed. p. 31-44

Marshall, D., Dombrowski, R., Garner, M. e Smith, K. (2010).The Accounting Education Gap. The CPA Journal, v. 80, n. 6, p. 6-10. June.

Mendoza, M. Á. G. (2001). Pedagogía: definición, métodos y modelos. Revista Ciencias Humanas, Colombia, v. 26, n. 4 [online]. Julio.

Moran, J. M. (2011). Desafios da educação a distância no Brasil. In: Arante, V. A. (Org.). Educação a distância: pontos e contrapontos. São Paulo: Summus. p. 45-86

Moreno, H. (2003). Modelos educativos y pedagógicos. In: MORENO, Herroro (Org.). Modelos educativos pedagógicos y didácticos. Bogotá: Editora Géminis. p. 11-95

Nossa, V. (1999). Formação do corpo docente dos cursos de graduação em Contabilidade no Brasil: uma análise crítica. Caderno FIPECAFI, n. 21, mai./ago.

Nóvoa, A. (2009). Professores: imagens do futuro presente. Lisboa: EDUCA Instituto de Educação da Universidade de Lisboa.

Ocaña, A. L. O. (2009). Manual para elaborar el modelo pedagógico de la institución educativa. Colômbia: Editorial Antillas.

Pereira, et al. (2011). Modelo pedagógico virtual da Universidade Aberta: para uma universidade do futuro. Lisboa: Universidade Aberta, 2011.

Peters, O. (2009). A educação a distância em transição: tendências e desafios. Tradução de Leila Ferreira de Souza Mendes. São Leopoldo: Editora Unisinos.

Piaget, J. (1973). Biologia e conhecimento. 2. ed. Tradução de Francisco M. Guimarães. Rio de Janeiro: Editora Vozes.

Piaget, J. (1995). Abstração reflexionante: relações lógico-aritméticas e ordem das relações espaciais. Porto Alegre: Artes Médicas.

Project Management Institute. (2008). Um guia do conjunto de conhecimentos em Gerenciamento de Projetos (Guia PMBOK®). 4 ed. Newtown Square.

Silva, K. K. A. (2012). Mapeamento de competências: um foco no aluno da Educação a Distância. Dissertação (Mestrado). Universidade Federal do Rio Grande do Sul, Porto Alegre.

Vendruscolo, M. I. e Behar, P. A. (2015). Professor competencies: analysis of a teaching competency matrix and its elements. In: International Conference of Education, Research And Innovation, 8th., Seville, 2015. Anais... ICERI2015 IATED, November 16-18, p. 1674-1682. 